\title{
Andrew Gamble. Crisis Without End? The Unravelling of Western Prosperity. New York: Palgrave Macmillan, 2014.
}

\section{Introdução}

Andrew Gamble, que foi professor nas universidades de Cambridge e Sheffield e editor da revista Political Studies, é um dos principais economistas políticos do Reino Unido, autor de obras influentes que incluem Britain in Decline; The Free Economy and the Strong State; Hayek - the Iron Cage of Liberty e Can the Welfare State Survive?. A força de suas análises muito se deve à forma como utiliza os novos paradigmas de economia política, integrando insights e contribuições da Economia e da Ciência Política.

A crise iniciada em 2007/2008 é uma das mais sérias da história do capitalismo. Apesar da magnitude, a crise foi gerenciada, impedindo que a recessão se transformasse em depressão. No entanto, as incertezas continuam altas e problemas centrais não foram equacionados. Passados dez anos, o crescimento não foi retomado de forma consistente.

A crise apresenta muitas particularidades. A despeito do endividamento e de medidas de expansão monetária, não houve inflação, mas deflação. Passada uma década, as taxas de juros permanecem próximas de zero. Outro aspecto foi a aparente resiliência do sistema político: até 2016, as democracias mostravam certa solidez, não tendo

Doutor pela Universidade de Sheffield. Professor da Escola de Governo Professor Paulo Neves de Carvalho - Fundação João Pinheiro, Belo Horizonte, MG, Brasil. E-mail: <alexandre.queiroz@fjp. mg.gov.br>. Agradeço à Capes pelo apoio financeiro. 
ocorrido nas principais democracias a chegada ao poder de candidatos que colocassem ameaças ao sistema. Em 2016, no entanto, a vitória de Donald Trump e a saída do Reino Unido da União Europeia sinalizaram para a emergência de um cenário mais conturbado.

Por trás da crise, há fatores estruturais. $\mathrm{O}$ mais visível é a arquitetura do sistema financeiro e a incapacidade de regulação de atividades altamente especulativas. Outras dificuldades incluem a deterioração da renda dos assalariados, que impacta a capacidade de consumo; e os desequilíbrios entre países credores e devedores, que contribuem para alimentar a ciranda financeira internacional. A crise engatilhou análises que vêm enfatizando a necessidade de novas regras para o sistema econômico internacional. No entanto, o sistema vigente vem demonstrando enorme resiliência: apenas pequenas mudanças foram adotadas e o colapso não foi capaz de abalar os pilares de um modelo muito centrado nas finanças.

Mudanças estruturais precisam ser adotadas para que os países ocidentais superem o que, segundo Gamble, parece uma crise sem fim. Uma dimensão central diz respeito às novas regras de governança internacional e à capacidade de incorporar os países em ascensão (rising countries). Isso passa pela política e pela necessidade de desbloquear caminhos e resolver três desafios (conundrums): o da governança, o do crescimento e o fiscal.

\section{A mudança global e a questão da governança}

A crise reflete mudanças na esfera internacional, com o crescimento do poder econômico dos países em ascensão não acompanhado das necessárias transformações institucionais. Houve progresso em tornar o G20 um fórum mais importante, mas é necessário fortalecê-lo e torná-lo mais efetivo. Mudanças são também necessárias nos critérios de participação e votos do Fundo Monetário Internacional, adequando-os à nova distribuição de forças, e na participação no Conselho de Segurança da ONU. O ponto é que existem dificuldades para atingir certos acordos: os países ricos estão interessados na manutenção do status quo, enquanto os rising countries demandam regras que lhes permitam avançar. Há o risco 
de uma ordem internacional fragmentada, com o recuo do multilateralismo e a proliferação de acordos bilaterais e regionais.

$\mathrm{O}$ argumento beneficia-se da comparação com outros contextos. Os anos entreguerras (1914-1945) foram de impasse, com a incapacidade de manter a paz e a prosperidade, principalmente após a Grande Depressão, que levou ao abandono do padrão ouro e à formação de blocos que prejudicaram o comércio internacional (GOUREVITCH, 1986). Essas lições foram aprendidas no pós-guerra, levando ao Plano Marshall e à reconstrução do Japão e da Alemanha. Entre os bens públicos que os EUA passaram a oferecer, incluem-se o enforcement de regras, a moeda internacional, a remoção de barreiras ao comércio e a garantia de segurança. Os EUA abriram mão de seus interesses de curto prazo, contribuindo para a construção da ordem internacional e para o crescimento mundial.

O problema, hoje, é que os EUA podem não mais possuir apetite ou capacidade para desempenhar um maior papel. A Guerra do Iraque os enfraqueceu e o isolou de seus aliados; a dívida externa e a dependência dos países asiáticos indicam certa fragilidade. Assim, a manutenção da liderança demanda ajustes e concessões que levem os outros países a aceitar a sua posição. Não obstante, vem havendo pouco avanço em direção a uma ordem multilateral, o que se agravou após o crash financeiro.

A Conferência em Londres, em 2009, buscou novas regras para a arquitetura financeira internacional, sendo aprovada a criação de uma nova instância para aprimorar a regulação das operações financeiras (Financial Stability Board). No entanto, os avanços foram menos abrangentes e compreensivos do que se esperava. Os fatores que estiveram na raiz da crise não foram enfrentados, incluindo o comportamento especulativo dos bancos e o fato de serem grandes demais para quebrar. A incapacidade de pensar globalmente e a falta de coragem para tocar em interesses estabelecidos pode empurrar a economia global para a próxima crise.

Enfim, houve, nas últimas décadas, forte expansão da ordem produtiva e financeira internacional, com a intensificação de forças fora do controle dos governos, incluindo empresas, finanças, ONGs 
e networks. Há o risco de anarquia, marcada por incapacidade de compartilhar regras, conflito sobre controle e distribuição de recursos e cooperação declinante. No outro extremo, há a possibilidade de uma ordem cosmopolita governada por instituições representativas que determinem regras universais a serem seguidas. Para Gamble, se há uma economia global, deveria também haver formas de política global. O desafio para a sua construção, entretanto, é substancial.

\section{O desafio (conundrum) do crescimento}

Acirrou-se também o debate sobre os desafios para o crescimento mundial. Os otimistas argumentam que a base científica e de inovação nunca foi tão grande e que o fluxo de inovação tende a crescer. Tecnologias como impressão em 3D e inovações em nanotecnologia, bioquímica, inteligência artificial e neurociência teriam alto potencial de transformação e impacto sobre a produtividade. A presença de um sofisticado sistema financeiro e de grandes empresas multinacionais tende também a contribuir. Enfim, há o potencial representado pela tarefa de levar serviços básicos de infraestrutura para milhões de pessoas nos países em desenvolvimento, com forte impacto sobre o investimento e o crescimento.

Do outro lado, os pessimistas enfatizam variáveis demográficas como as baixas taxas de natalidade e o envelhecimento da população. A imigração, uma possível solução, esbarra na oposição política que desperta em vários países. Um segundo fator diz respeito ao alto endividamento das famílias, empresas e bancos: em um contexto de alto endividamento e baixas expectativas, os investimentos tendem a continuar baixos. Nesse sentido, diversos países poderiam vir a compartilhar a "doença japonesa", atolando-se em um ciclo de baixo crescimento, deflação e demanda reprimida. ${ }^{2}$ Os pessimistas argumentam, também, que as inovações com capacidade de aumentar a taxa de crescimento são poucas. A internet, apesar de revolucionária,

\footnotetext{
2 "Japan became locked into a cycle of low growth and deflation which proved very hard to break. (...) It is often cited as an example of what could happen to other western economies in this new period after the crash." (GAMBLE, 2014, p.141).
} 
não teria impactos sobre os investimentos na magnitude ocorrida com a energia a vapor e a eletricidade.

Uma questão central diz respeito ao meio ambiente. Considera-se que o crescimento dos últimos 200 anos foi excepcional, por ter sido possível crescer sem se preocupar com o meio ambiente. Os danos atuais e o aquecimento global, no entanto, indicam a impossibilidade de se emular o padrão de consumo norte-americano. ${ }^{3}$ Mesmo que não haja esgotamento dos recursos, pode haver conflitos sobre o acesso à água e à energia. Uma solução favorável aponta para uma "revolução de baixo carbono", com prioridade para a segurança energética e a garantia de tecnologias sustentáveis. Trata-se de uma agenda, no entanto, que tende a entrar em choque com as perspectivas de crescimento econômico rápido.

$\mathrm{O}$ crescimento mundial pode ser favorecido pelo bom desempenho dos países menos desenvolvidos. Essa possibilidade depende, no entanto, de uma ordem internacional que facilite a transferência de empréstimos e investimentos. As agendas da governança e do crescimento se aproximam: avanços na cooperação internacional tendem a ser essenciais para a emergência de um novo ciclo virtuoso.

Segundo Gamble, os políticos e o público precisam encarar a possibilidade de que o crescimento não volte da forma antiga e de que possa haver um período prolongado de baixo crescimento e reestruturação. Os otimistas argumentam que todas as vezes em que houve impasse, o capitalismo se renovou. Mas, desta vez, pode ser diferente, dados os impasses da ordem neoliberal e os desafios em questão. O problema é que a legitimidade pode ser afetada, abrindo espaço para partidos antissistema.

\section{O desafio fiscal}

$\mathrm{O}$ estado de bem-estar (EBS) consolidado no pós-guerra previa ampla oferta de serviços e garantia de direitos. O problema surgiu com o agravamento das dificuldades fiscais, resultado da

3 Para um aumento de dois graus na temperatura mundial em 2050, a emissão de carbono precisa se reduzir para 2 toneladas por pessoa; hoje, encontra-se em 24 nos EUA, 10 a 12 na Europa e seis na China (GAMBLE, 2014, p. 149). 
desaceleração econômica e de mudanças demográficas, entre outros fatores (GAMBLE, 1988). Há, desde então, dificuldades para financiar o EBS, com impactos negativos sobre a legitimidade. Isso se explica pela dificuldade em ampliar os impostos, resultado da desconfiança de muitos atores em relação aos governos (Gamble, 2016). O quadro é agravado pelo aumento da desigualdade e pelos impactos negativos sobre a coesão social (Streeck, 2012).

As dificuldades são mais sérias nos países da Eurozona, que não contam com a política cambial e um banco central próprio. A forma de responder aos desafios econômicos vem sendo preponderantemente via cortes nos gastos públicos e nos salários, tentando recuperar a rentabilidade dos investimentos. Mas com a queda na arrecadação, governos têm de tomar mais recursos emprestados, agravando o quadro fiscal. O ponto é que a austeridade requerida tem sido grande demais, tendendo a fortalecer partidos contrários à União Europeia. Para Gamble, ou a eurozona caminha para a união fiscal ou abandona a moeda única. Outra possibilidade seria a adoção de um "Plano Marshal" capaz de dar esperança aos cidadãos. Se não romper o impasse, tende a produzir uma crise sem fim.

\section{Caminhos para o futuro}

O poder de recuperação das economias capitalistas sempre foi formidável, mas, desta vez, a recuperação pode ser lenta, ameaçando a democracia e a ordem internacional. No contexto de uma crise, demora certo tempo para que os efeitos sejam percebidos. $\mathrm{O}$ mundo será diferente em 2050: lá saberemos se a China continuará a crescer ou se implodirá; se o aquecimento global se agravará e se a União Europeia sobreviverá.

Gamble traça quatro cenários, concebidos como tipos ideais. O primeiro é de primazia dos EUA: o sistema internacional continua unipolar e sem a ocorrência de mudança fundamental de poder para o oriente. A União Europeia continuará uma associação frouxa de estados, e a relação entre Rússia e Estados Unidos continuará complicada, mas sem degenerar em conflito aberto. Nesse cenário, o desafio dos países em ascensão é derrotado ou adiado 
indefinidamente. Concessões são feitas e esses países optam por se integrar à ordem ocidental aceitando a liderança americana; seu progresso é desigual, e até 2050 não emergem como sociedades industriais totalmente maduras.

Nesse cenário, os EUA continuam à frente em muitas tecnologias e na criação de marcas globais. Republicanos e democratas administram os conflitos e priorizam manter as finanças sob controle. $\mathrm{O}$ problema do déficit externo torna-se gerenciável e o dólar continua a ser a moeda internacional. As autoridades mostram capacidade de regulação para prevenir outro crash financeiro. Enfim, o custo de manter estados de bem-estar amplos é agravado e cortes nos gastos sociais são adotados para reavivar a economia.

No cenário 2, a China recusa uma integração plena na ordem ocidental e procura desafiá-la. Mas as tensões entre China e EUA não conduzem a um conflito aberto. A China avança e se consolida como montadora de inúmeros bens industriais, mas continua a ter uma pequena fração do poder militar dos EUA, o que pode mudar se vier a dominar o setor de tecnologia da informação. A presença de um estado autoritário torna sua ascensão algo enigmática.

Os Estados Unidos continuam a precisar que a China compre os títulos de sua dívida e essa o faz por não ter o que fazer com as reservas; a posse dos títulos, no entanto, lhe dá poder de barganha. A China pode permitir tornar sua moeda conversível, o que levaria à apreciação de valor e ao fortalecimento do mercado interno. Mas prejudicaria as exportações, muito importantes para o emprego de milhões de chineses (JACQUES, 2012). Nesse cenário, os EUA tenderiam a aprofundar iniciativas como a Parceria Transatlântica de Comércio e Investimento e a Parceria Transpacífica. No geral, as instituições internacionais tornar-se-iam menos capazes de lidar com os conflitos e com outras questões de interesse global.

No terceiro cenário, mudanças de poder e riqueza conduzem a um mundo multipolar. Os EUA decidem compartilhar a liderança com outros membros do G20, construindo uma ordem internacional centrada em negociações multilaterais em tópicos como meio ambiente, comércio, imigração e proliferação nuclear, entre outros. 
Enfrenta-se, assim, o desafio de transformar uma ordem muito centrada no ocidente em outra capaz de incorporar outros países, 0 que implica aumentar a solidez das instituições e acomodar diferentes interesses. $\mathrm{O}$ equacionamento de questões relacionadas a comércio, investimento, finanças e clima contribui para um novo ciclo de crescimento e prosperidade. Esse cenário, no entanto, depende de grande capacidade de negociação e, particularmente, da disposição dos EUA em fazerem concessões, inclusive por parte do Congresso.

No quarto cenário, os EUA abrem mão de sua liderança para focar em questões internas; o esforço para manter o mundo coeso passa a ser considerado grande demais. Como consequência, a economia internacional fragmenta-se em agrupamentos regionais, que limitam a exposição ao mercado global e adotam formas de proteção e controle. $\mathrm{O}$ mundo se divide em esferas de influência, podendo surgir conflitos em questões como acesso à água e a fontes de energia, entre outras. Os conflitos tendem a ser localizados, com o risco de escalada, a depender do envolvimento das grandes potências. Assim, instituições internacionais são preservadas, mas tratando temas de pouca substância e pouco contribuindo para a cooperação internacional. A questão demográfica continua a se agravar, enquanto considerações políticas domésticas impedem a livre movimentação do trabalho. $\mathrm{O}$ colapso da Eurozona não é descartado.

\section{Considerações finais}

Com juros próximos a zero e a principal recessão desde 1945, um cenário de crescimento sustentado parece distante. Apenas o terceiro cenário considera o aumento dos recursos políticos para enfrentar o impasse, em um processo que envolveria enorme esforço de construção institucional. Levar os avisos ambientais a sério implica mudanças no estilo de vida e na forma como o crescimento foi alcançado. Significa mudanças radicais, difíceis de serem imaginadas nos procedimentos da política atual.

Há dificuldades em impor mudanças em uma ordem internacional que se mostrou no passado tão bem-sucedida. Muitos atores não estão prontos para enfrentar os desafios, o que contribui para 
a perpetuação da crise. Enfrentam-se os sintomas, mas não os problemas estruturais. Por miopia e inércia, o mundo pode deslizar para a fragmentação e para impasses profundos. Em face dessa ameaça, retomar a prosperidade demanda estruturas de governança que fortaleçam a cooperação, assim como um modelo de crescimento que equacione as ameaças ao meio ambiente.

O livro de Gamble, ao lidar com várias dimensões da crise, fornece um rico panorama do futuro que se prefigura. Tendo abordado o período de 2007 a 2014, Gamble enfatiza o puzzle da resiliência da democracia a despeito da incapacidade de se enfrentar o impasse e propor alternativas. Eventos posteriores sinalizam para ameaças mais concretas de recuo da democracia e de desdobramentos internacionais que se aproximam do quarto cenário, o mais preocupante. Apesar de significativas exceções, há ainda no Brasil certa dissociação entre a ciência política e a economia. A análise de Gamble atesta a riqueza e as possibilidades analíticas de abordagens que integrem a economia e a política entre si e com tópicos afins à área de relações internacionais.

\section{Referências}

GAMBLE, Andrew (1988) The free economy and the strong state.

Durham: Duke University Press.

GAMBLE, Andrew (2016) Can the welfare state survive? Cambridge: Polity Press.

GOUREVITCH, Peter (1986) Politics in hard times: comparative responses to internacional economic crises. Ithaca and London: Cornell University Press.

JACQUES, Martin (2012) When China rules the world: the end of the western world and the birth of a new global order. London: Penguin Books.

STREECK, Wolfgang (2012). "As crises do capitalismo democrático".

Revista Novos Estudos Cebrap. 92, março, p. 35-56. 


\section{Resumo}

O artigo discorre sobre as dimensões política, econômica, doméstica e internacional da crise econômica iniciada em 2007-2008. Procura situar os impasses e particularidades da crise, entender a sua gravidade e resiliência e explorar cenários para os anos seguintes. Para isso, aborda três desafios centrais: os desafios de governança, de crescimento e fiscal. Em sequência, explora quatro possíveis cenários para a ordem econômica internacional. Em apenas um deles há efetiva preocupação com o fortalecimento da capacidade institucional para enfrentar o impasse. Assim, por miopia e inércia, o mundo pode deslizar para a fragmentação e para um beco sem saída. Evitar esse cenário requer estruturas de governança que fortaleçam a cooperação e um modelo de crescimento que possa reverter as ameaças ao meio ambiente.

Palavras chave: crise econômica; ordem internacional; meio ambiente; governança internacional; crescimento econômico; economia política

\section{Abstract}

The article deals with the political, economic, domestic and international dimensions of the international crisis initiated in 2007-2008. It intends to grasp its impasses and peculiarities, to understand its gravity and resilience and explore paths to the future. In order to do that, explores three key conundrums: the governance, the growth and the fiscal conundrums. Then, it deals with four alternative paths which may be followed by the international order. In only one there is significant concern to strengthen the institutional capacity to deal with the impasses. As a consequence, the world order may disintegrate and degenerate in fragmentation and deadlock. The avoidance of this scenario requires governance structures which strengthen cooperation and a growth model able to revert the threatens to the environment.

Keywords: economic crisis; international order; environment; international governance; economic growth; political economy

Recebido em 25 de dezembro de 2016 Aprovado em 5 de dezembro de 2017 